\title{
Combined medial patellofemoral and medial patellotibial reconstruction for patellar instability: a PRISMA systematic review
}

\author{
Rocco Aicale ${ }^{1,2^{*}}$ and Nicola Maffulli $1,2,3,4$
}

\begin{abstract}
Background: The medial patellofemoral ligament (MPFL) works in association with the medial patellotibial ligament (MPTL) and the medial patellomeniscal ligament (MPML) to impart stability to the patellofemoral joint. The anatomy and biomechanical characteristics of the MPFL have been well described but little is known about the MPTL and MPML. Several reconstruction procedures of the MPFL with semitendinosus, gracilis, patellar and quadriceps tendons, allografts and synthetic grafts have been described. No clear superiority of one surgical technique over another is evident.

Methods: A systematic review of the literature was conducted using PRISMA guidelines. Inclusion criteria were articles that reported clinical outcomes of combined reconstruction of MPTL and MPFL. The methodological quality of the articles was determined using the modified Coleman Methodology Score (CMS).

Results: Nine articles were included, reporting the clinical outcomes of 197 operated knees. The surgical procedures described include hamstrings grafting and transfer of the medial patellar and quadriceps tendons with or without bony procedures to reconstruct the MPTL in association with the MPFL. Overall, good and excellent outcomes were achieved. The median CMS is $70.6 \pm 14.4$ (range 38 to 84).

Conclusion: Different techniques are reported, and outcomes are good with low rates of recurrence. The quality of the articles is variable, ranging from low to high. Appropriately powered randomized controlled trials are needed to better understand what the adequate indications for surgery in patients with patellar instability and clinical outcomes are. Combined reconstruction of MPFL and MPTL leads to favourable clinical outcomes, supporting its role as a valid surgical procedure for patellar stabilization.
\end{abstract}

Keywords: MPTL, MPFL, Medial patellotibial ligament reconstruction, Medial patellofemoral ligament reconstruction, Patellar dislocation reconstruction

\footnotetext{
*Correspondence: aicale17@gmail.com

'Department of Musculoskeletal Disorders, Faculty of Medicine and Surgery, University of Salerno, 84084 Baronissi, Italy

${ }^{2}$ Clinica Ortopedica, Ospedale San Giovanni di Dio e Ruggi D’Aragona, 84131 Salerno, Italy

Full list of author information is available at the end of the article
}

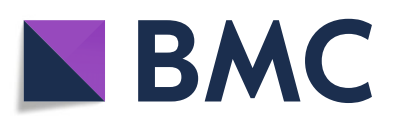

(- The Author(s). 2020 Open Access This article is licensed under a Creative Commons Attribution 4.0 International License, which permits use, sharing, adaptation, distribution and reproduction in any medium or format, as long as you give appropriate credit to the original author(s) and the source, provide a link to the Creative Commons licence, and indicate if changes were made. The images or other third party material in this article are included in the article's Creative Commons licence, unless indicated otherwise in a credit line to the material. If material is not included in the article's Creative Commons licence and your intended use is not permitted by statutory regulation or exceeds the permitted use, you will need to obtain permission directly from the copyright holder. To view a copy of this licence, visit http://creativecommons.org/licenses/by/4.0/. The Creative Commons Public Domain Dedication waiver (http://creativecommons.org/publicdomain/zero/1.0/) applies to the data made available in this article, unless otherwise stated in a credit line to the data. 


\section{Introduction}

Lateral patellar dislocation is a common cause of knee injuries and anterior knee pain, associated with haemarthrosis, especially in young patients $[1,2]$. The patella is stabilized by ligaments, muscle and the trochlear groove [3]. The major stabilizing ligamentous structure, the medial patellofemoral ligament (MPFL), works in association with the medial patellotibial ligament (MPTL) and the medial patellomeniscal ligament (MPML) to impart stability to the patellofemoral (PF) joint [4]. The MPFL is considered the major medial restrictor while the others are secondary [5]. Patella alta, a large Q angle, a hypoplastic lateral femoral condyle and congenital ligamentous laxity are associated to recurrent patellar dislocation [6]. The MPTL and MPML contribute to limit the lateral translation of the patella, and this contribution increases from $26 \%$ in extension to $46 \%$ at $90^{\circ}$ of flexion [1].

The anatomy [7], imaging [8, 9] and biomechanical characteristics $[1,5]$ of the MPFL have been well described, but little is known about the MPTL and MPML $[1,5,8-10]$. The MPTL is located $13.7 \mathrm{~mm}$ distal to the joint line and $3.6 \mathrm{~mm}$ proximal to the distal border of the patella, $9.4 \mathrm{~mm}$ distal to the joint line and in line with the medial border of the medial tibial spine [11]. When choosing a graft for reconstruction, it must be considered that the MPTL is stiffer than the MPFL. The MPTL and MPML, though considered secondary restrictors, have an important role in maintaining joint stability, especially in the final phases of extension, opposing the lateral traction of the quadriceps [12, 13].

The choice of technique to restore the stability of the PF joint needs to consider the skeletal maturity of the patient to avoid injury to the distal femoral physis [14-16]. The recommended treatment for recurrent patellar dislocation, in patients with normal bony morphology, is ligamentous reconstruction [17]. This usually involves MPFL reconstruction with the addition of procedures that improve, in specific cases, the alignment and the congruence of the patellofemoral joint [18], although isolated MPFL reconstruction produces good results [19-21]. Furthermore, good results with low complication rates are obtained with combined MPTL and MPFL reconstruction [22-24]. To the best of our knowledge, no studies compared outcomes of isolated reconstruction of the MPFL versus isolated reconstruction of the MPFL, or combined reconstruction of both ligaments versus isolated reconstruction of either of them. Combined MPTL and MPFL reconstruction may improve the outcomes compared to isolated reconstructions of either of them and/or decrease the need for other procedures, such as tibial tuberosity osteotomies (TTO), reducing surgical morbidity [24].

Historically, probably the first technique to surgically manage patellar instability was the Galeazzi procedure described in 1922, using a semitendinosus (ST) patellar tenodesis [25]. This procedure continued to be performed even in 1998, when the precise anatomical location of the insertion of MPFL was reported [20]. Rillmann et al. [20] described a transfer of the medial portion of the patellar tendon (PT). Both surgical techniques are analogous to a MPTL reconstruction. Many other authors reported their results with these techniques, with or without the reconstruction of the MPFL (e.g. lateral retinaculum release, TTO, Roux-Goldthwait) [26-28]. In the early 2000s, following the introduction of the isolated MPFL reconstruction, MPTL reconstruction fell out of favour. More recently, however, combined MPFL and MPTL reconstruction has been reported [13, 14, 22-24, 29-32].

An adequate tensile strength and length of the graft are the most important features for an ideal graft for combined reconstruction. In addition, the graft should have similar stiffness compared to the original ligaments to be reconstructed. The most commonly used grafts for ligaments reconstruction in the knee include the quadriceps, patellar, semitendinosus and gracilis tendons: all provide adequate strength in reconstruction procedures. However, because the MPTL is stiffer than the MPFL, the use of a stiffer graft for the MPTL than for the MPFL can be considered [11].

The purpose of this PRISMA compliant systematic review is to report techniques and clinical outcomes of reconstruction of the MPTL in combination with MPFL reconstruction in patients with lateral PF instability.

\section{Methods}

This systematic review and its procedures were organized, conducted and reported following the Preferred Reporting Items for Systematic Reviews and Meta-Analyses (PRISMA) guidelines [33-35]. The PRISMA checklist is presented in Fig. 1.

We performed a systematic search (up to August 2020) in the PubMed and Scopus electronic databases to identify the available scientific articles about techniques and clinical outcomes of reconstruction of MPTL in combination with the MPFL in patients with lateral PF instability, with no restrictions of time and language.

For the purposes of our systematic review, we used several combinations of the following keywords: MPTL, MPFL, medial patellotibial ligament reconstruction, medial patellofemoral ligament reconstruction and patellar dislocation reconstruction. Editorials, technical notes, letters to authors, narrative reviews, systematic review articles and articles that did not report any clinical outcomes were excluded. Eligible articles could have been published in English, French, Italian, Spanish and Portuguese.

An orthopaedic resident (RA) performed the search and evaluated the articles. An experienced researcher in systematic reviews (NM) solved cases of doubt. At the beginning of the procedure, the investigator read the 


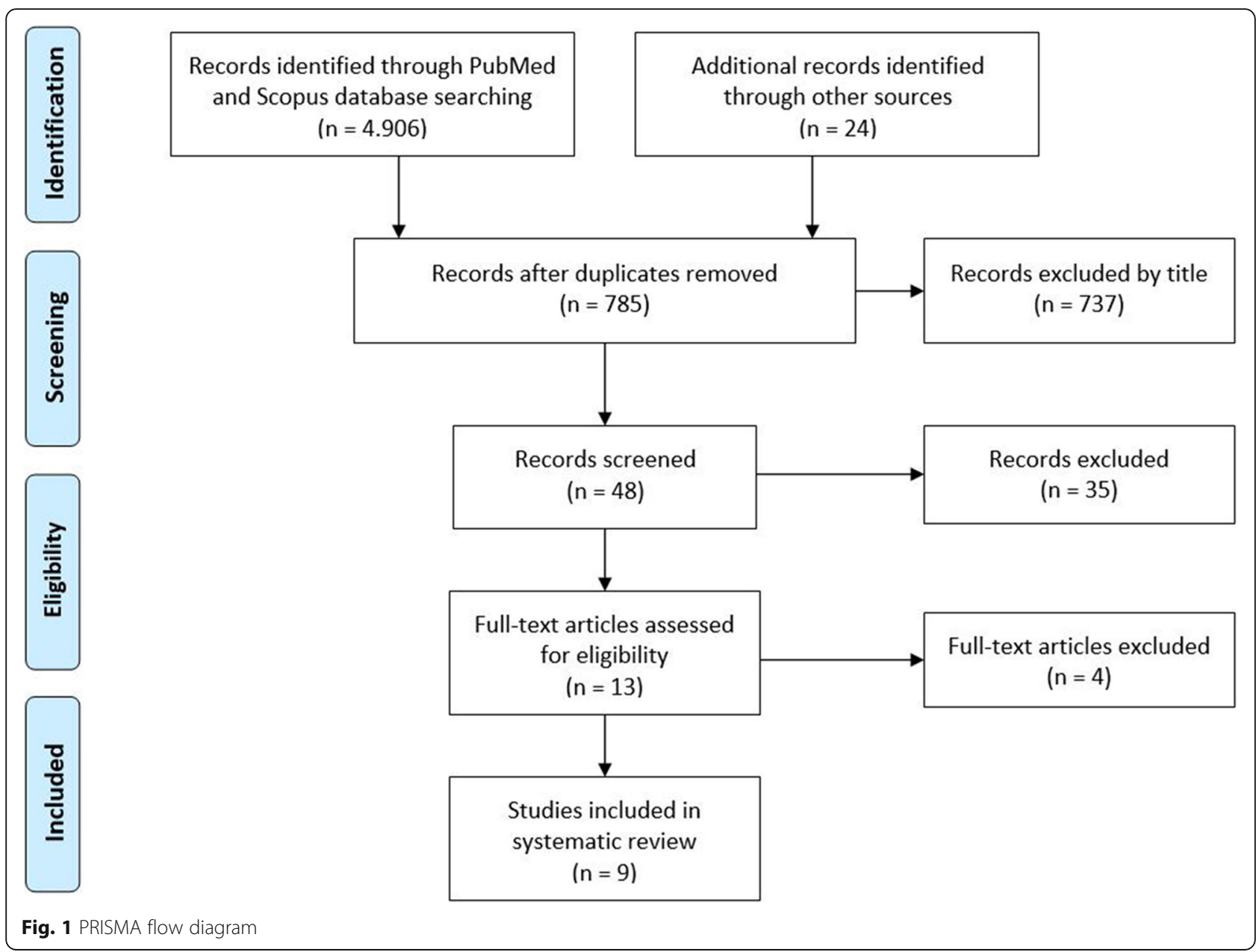

abstracts of all the articles, selected the relevant ones according to both inclusion and exclusion criteria and then compared the results with the other investigator. After 1 week, the same studies were read again to confirm the investigators' agreement regarding articles selected. No disagreement was observed among the investigators.

The Coleman Methodology Score (CMS) was used to evaluate the quality of the articles included in this PRIS MA systematic review [36]. The two authors (RA and NM) applied independently the CMS, and a final score was reached by consensus. The CMS is calculated by adding ten different criteria (study size, follow-up, number of procedures, type of study, diagnostic certainty, description of surgical technique, rehabilitation and compliance, outcome criteria, outcome assessment and selection process), with a maximum total possible score of 100 [36].

One investigator extracted the data from the full-text articles to Excel spreadsheet structured tables to analyse each study in a descriptive fashion. Another investigator independently double-checked the extraction of primary data from all the articles. Doubts and inconsistencies were grouped and solved. The information extracted from the articles is listed in Table 1.

\section{Results and discussion}

After the initial literature search, a total of 4906 potentially relevant citations were identified. After removal of duplicate records, 785 articles were identified. After a first check of titles and abstracts, 737 articles were not included, since they did not investigate the outcomes of reconstruction of the MPTL in combination with the MPFL in patients with lateral PF instability. After further screening, other 39 articles were excluded since they did not conform to the inclusion criteria. A total of 9 articles (Table 1) were included in the present systematic review. The study selection process is reported in the PRISMA flowchart (Fig. 1). No randomized control trials were identified in our search, and all articles are case reports or case series.

Results of the CMS are reported in Table 2. There was a large range of CMS values, from 38 to 84 , with a mean of $70.6 \pm 14.4$. Some of the selected studies reported a 


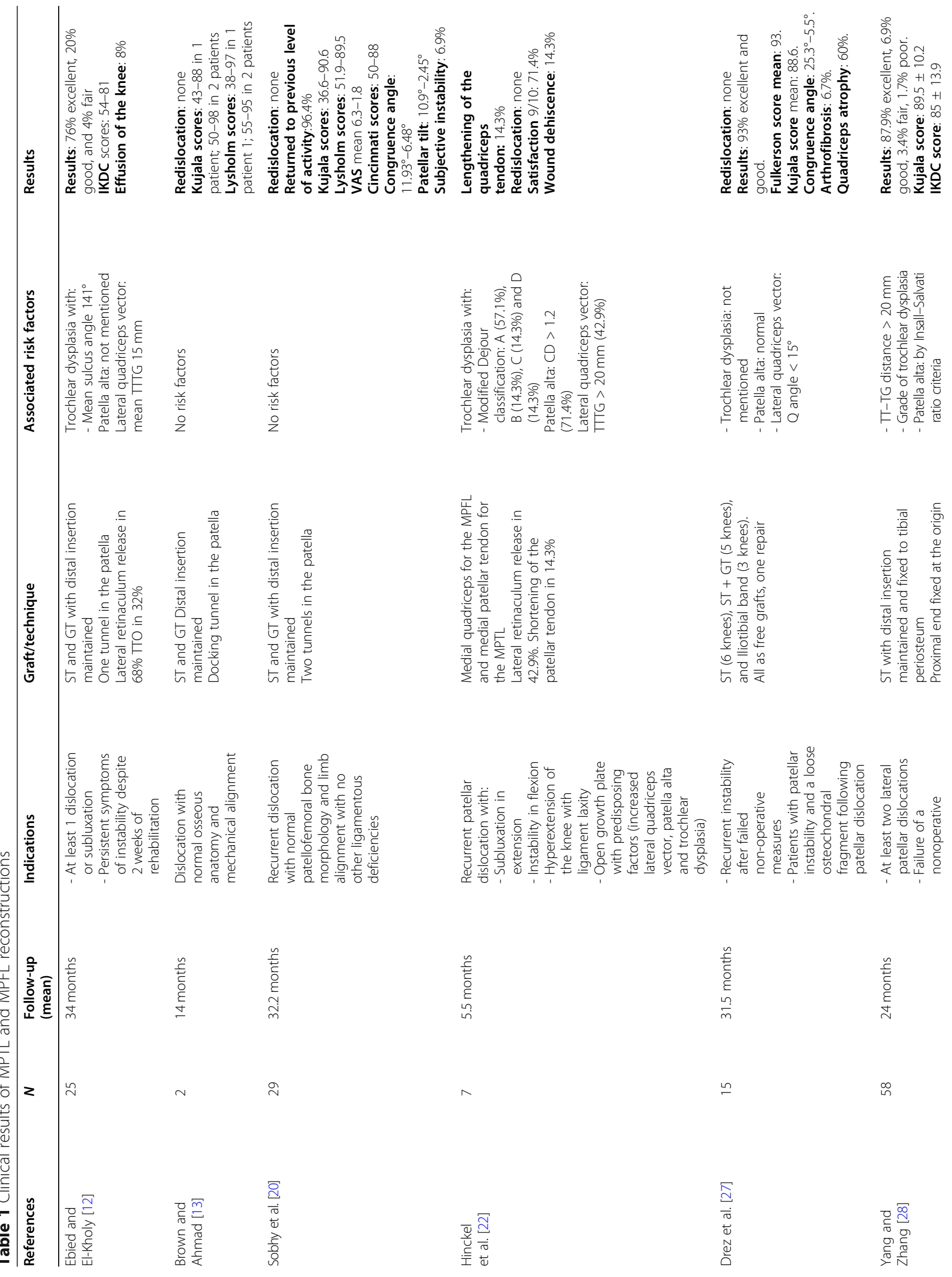




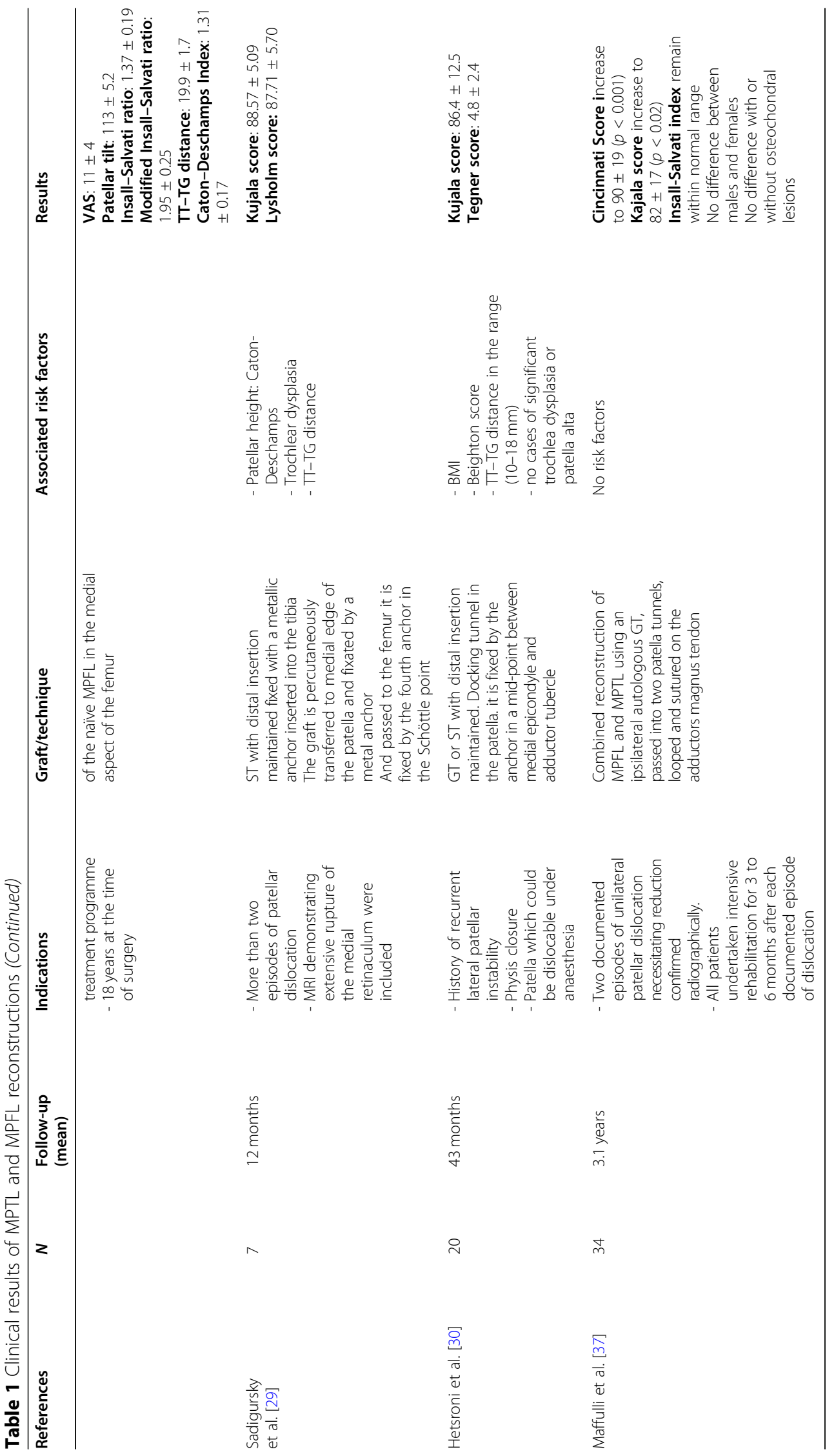




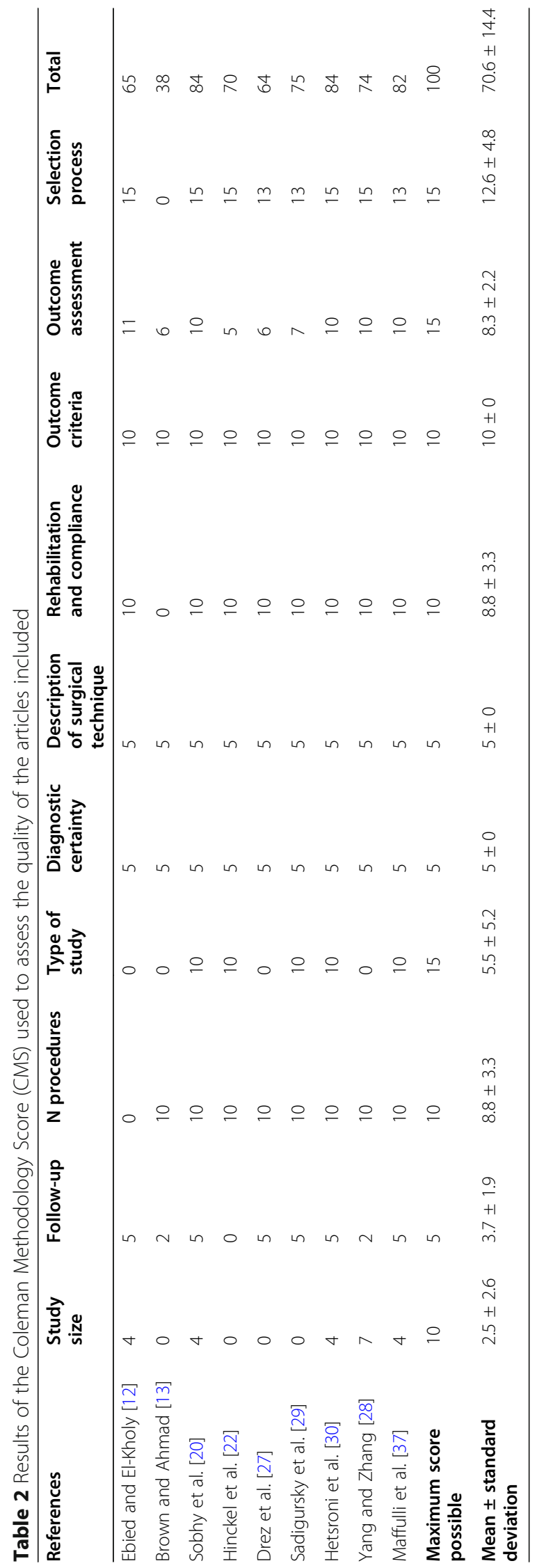


relatively small cohort of patients; had short follow-up, unclear outcome criteria and assessments and poor patient selection processes; and were retrospective.

In the analysed studies, most authors used hamstrings autografts, such as the gracilis tendon [37], preserving their tibial attachment [13, 14, 22, 30, 32]. In particular, two had free ends fixed in the tibia [24, 29,31], eight used hamstrings [13, 14, 22, 29-32, 37], and one used the medial portion of the patellar and quadriceps tendons using anchors to fix the grafts in femoral and tibial attachments [24].

Furthermore, in three studies femoral tunnel fixation was undertaken using interference screws, with the proximal end of the hamstring graft employed to reconstruct the MPFL $[13,22,30]$, in three other studies anchors were used to fix the semitendinosus grafts to the femur $[29,31,32]$, while in one study the free end of the graft was looped and sutured to the adductor magnus tendon [37].

In this systematic review, we found many different techniques with wide variation in the graft choice, harvesting and fixation. The lengths of the various graft were different: $8.8 \pm 8.4 \mathrm{~cm}$ for the quadriceps tendon [38], $4.9 \mathrm{~cm}$ for the patellar tendon [39], $36.6 \mathrm{~cm}$ for the semitendinosus tendon [39] and $41.9 \mathrm{~cm}$ for the gracilis tendon [39]. All grafts were long enough to reconstruct the MPFL (mean length of $60.6 \mathrm{~mm}$ ) and MPTL (mean length of $36.4 \mathrm{~mm}$ ) [7].

The tensile strength values were the following: for the quadriceps tendon, $1 \mathrm{~cm}$ in diameter of the superficial layer (stiffness of $33.6 \pm 6.8 \mathrm{~N} / \mathrm{mm}$; yield load of $147.1 \pm$ $65.1 \mathrm{~N}$, maximum load to failure of $205 \pm 77.8 \mathrm{~N}$ ) [40]; for the medial third of the patellar tendon, $2734 \pm 298 \mathrm{~N}$ [39]; for the semitendinosus tendon, $1216 \pm 50 \mathrm{~N}$ [39]; and for the gracilis tendon, $838 \pm 30 \mathrm{~N}$ [39].

The complications reported included wound infections [29, 41], quadriceps atrophy and subjective instability complaints [32], limitation of the range of motion (ROM) [22, 29] and effusion of the knee [13]. Three studies reported no complications in a total of $67 \mathrm{pa}$ tients [14, 30, 31]. Wound complications, in a recent systematic review, were $11.9 \%$ overall, which may be related to extensive exposure and releases performed [42].

The present work identified a low number of articles that meet inclusion criteria $(N=9)$, with a relatively small number of operated knees $(N=197)$, reporting eight different techniques, all producing favourable outcomes with low rates of redislocation. The quality of articles is variable, from low to high.

Management of patellar instability with combined reconstruction of the MPFL and MPTL lacks of level I evidence which compares surgical techniques and biomechanical principles behind the mentioned techniques. Bitar et al. [43] compared operative and nonoperative management for recurrent patellar instability, with better subjective outcome after surgical treatment with MPFL reconstruction. The use of femoral soft-tissue fixation for MPFL reconstruction may reduce surgical morbidity but could be inferior in relation to patellar stability and patellar tracking; furthermore, it could result in an inferior clinical outcome compared with bone fixation of the graft. A recent RCT confirms that soft-tissue graft fixation did not result in an inferior subjective clinical outcome compared with screw fixation. Also, surgical morbidity at the femoral condyles was similar to those associated with screw fixation, with both techniques associated with an $11 \%$ incidence of significant pain at the femoral condyle with excellent patellar stability [44].

Generally, in the reported articles, patients had no additional risk factors for patellar instability. However, Ebied and El-Kholy performed a TTO in $32 \%(N=8$ of 25) of patients to correct a large quadriceps vector [13]. Hinckel et al. [24], in a study of 7 patients, reported a high-grade of trochlear dysplasia in 3 patients (43\%), patella alta in 5 patients (71\%) and a large quadriceps vector in 3 patients (43\%), but only in one patient (14\%), the patellar tendon was shortened.

Combined reconstruction of MPFL and MPTL is receiving increasing interest, probably due to new anatomical, biomechanical and histological studies which showed that the MPTL is a true ligament, with specific biomechanical proprieties important for patellofemoral tracking and stability $[11,45]$. Probably, combined reconstruction may improve outcomes if compared with isolated MPFL reconstruction [13, 14, 22, 29], reducing not only surgical morbidity decreasing the need of bony procedures such as TTO in patients with borderline patella alta/lateralized force vector, but also the use of trochleoplasty in patients with moderate dysplasia [41].

Rehabilitation protocols are different and vary from restrictive (progressive weight-bearing with a brace locked in extension for 2 weeks, then ROM gradually increases in $30^{\circ}$ increments every 2 weeks, and after 8 weeks the brace is discontinued and full weight-bearing and full range of motion are allowed) [22], to partially restrictive (full weight-bearing with crutches and isometric quadriceps strengthening, progressive increase of ROM to $0^{\circ}-$ $30^{\circ}$ for the first 2 weeks, to $0^{\circ}-90^{\circ}$ for the fifth and sixth weeks, when the brace is removed and ROM allowed without restrictions) [32].

In the future, routine reconstruction of both MPFL and MPTL may become a part of the algorithms used for the management of patellar instability. However, as a meta-analysis was not possible, we can only conclude that good clinical outcomes were achieved by combined MPFL and MPTL reconstruction. In any case, it should be considered that most patients do well with isolated reconstruction of the MPFL [46-48], and it is not clear when a reconstruction of the MPTL should be added. 
Given the lack of randomized controlled trials and the low number of studies, we are unable to define the ideal situation for combined MPTL and MPFL reconstruction. Probably, the indications suggested by Hinckel et al. [24, 49] (subluxation in extension, instability in flexion, knee hyperextension with ligamentous laxity, and skeletal immaturity with associated risk factors), supported by anatomical and biomechanical studies, may be used, at least until stronger clinical evidence is available.

The modified Coleman score [36] shows, on average, that the studies were of moderate quality, and the greatest limitation of this systematic review probably lies in the design of the reported studies. There are no randomized controlled trials comparing reconstruction of the MPFL and MPTL versus non-operative treatment, or comparing different operative treatments, and no article included a control group. Given the heterogeneity and small size of the cohorts studied, and the lack of randomized trials, a meta-analysis could not be performed.

A major strength of the present systematic review is the strict adherence to the PRISMA protocol and the use of accurate inclusion and exclusion criteria, which made our study reliable, since all the most up-to-date scientific evidence about the topic were meticulously examined.

Over the last few years, there has been increasing interest to the basic science and anatomic reconstruction of the MPFL and MPTL. At present, there is no clear consensus regarding the best technique to reconstruct the MPFL, and combined reconstruction of the MPTL and the MPFL could be effective in restoring patellar stability in patients with recurrent patella-femoral dislocation. We do not know whether such combined reconstruction would improve the outcomes relative to isolated MPFL or MPTL reconstructions, possibly decreasing the need for correction of other risk factors by osteotomies, thereby reducing surgical morbidity. We are aware that this can only be tested by appropriately powered randomized controlled trials.

Combined MPFL and MPTL reconstruction is safe and effective and allows surgeons to include these procedures in their surgical armamentarium for the management of recurrent patellar instability.

\section{Conclusions}

The available scientific literature regarding combined MPTL and MPFL reconstruction suggests that this procedure leads to favourable clinical outcomes with minimal morbidity, supporting its use as a valid surgical alternative for the management of recurrent lateral patellar dislocations and clinical instability. However, the quality of the scientific articles available is variable, from low to high, and appropriately powered randomized controlled trials are needed to better understand what the adequate indications for surgery in case of patellar instability are.

\section{Abbreviations}

MPFL: Medial patellofemoral ligament; MPML: Medial patellomeniscal ligament; MPTL: Medial patellotibial ligament; CMS: Coleman Methodology Score; PF: Patellofemoral; TTO: Tibial tuberosity osteotomies;

ST: Semitendinosus; GT: Gracilis tendon; PT: Patellar tendon; PRIS MA: Preferred Reporting Items for Systematic Reviews and Meta-Analyses; ROM: Range of motion

\begin{abstract}
Authors' contributions
One medical doctor (RA) performed the search of articles in the available scientific literature, while the researcher with more experience (NM) solved cases of doubt. At the beginning of the procedure, each examiner read the abstracts of all articles and selected the relevant ones. After 1 week, the same studies were read again to establish the agreement of the researchers on the selection. Each author has contributed to writing the manuscript. The authors read and approved the final manuscript.
\end{abstract}

Funding

The authors declare that they did not have used any funding.

Availability of data and materials

Not applicable

Ethics approval and consent to participate

Not applicable

Consent for publication

Not applicable

\section{Competing interests}

The authors declare that they have no competing interest.

\section{Author details}

'Department of Musculoskeletal Disorders, Faculty of Medicine and Surgery, University of Salerno, 84084 Baronissi, Italy. ${ }^{2}$ Clinica Ortopedica, Ospedale San Giovanni di Dio e Ruggi D'Aragona, 84131 Salerno, Italy. ${ }^{3}$ Barts and the London School of Medicine and Dentistry, Centre for Sports and Exercise Medicine, Queen Mary University of London, Mile End Hospital, 275 Bancroft Road, London E1 4DG, England. ${ }^{4}$ Faculty of Medicine, School of Pharmacy and Bioengineering, Guy Hilton Research Centre, Keele University,

Thornburrow Drive, Hartshill, Stoke-on-Trent ST4 7QB, England.

Received: 3 April 2020 Accepted: 5 November 2020

Published online: 12 November 2020

\section{References}

1. Philippot R, Boyer B, Testa R, Farizon F, Moyen B. The role of the medial ligamentous structures on patellar tracking during knee flexion. Knee Surg Sports Traumatol Arthrosc Off J ESSKA. 2012;20:331-6.

2. Vetrano M, Oliva F, Bisicchia S, Bossa M, De Carli A, Di Lorenzo L, et al. I.S. Mu.L.T. first-time patellar dislocation guidelines. Muscles Ligaments Tendons J. 2017:7:1-10.

3. Baldwin JL. The anatomy of the medial patellofemoral ligament. Am J Sports Med. 2009;37:2355-61.

4. Baumann CA, Pratte EL, Sherman SL, Arendt EA, Hinckel BB. Reconstruction of the medial patellotibial ligament results in favorable clinical outcomes: a systematic review. Knee Surg Sports Traumatol Arthrosc Off J ESSKA. 2018; 26:2920-33

5. Conlan T, Garth WP, Lemons JE. Evaluation of the medial soft-tissue restraints of the extensor mechanism of the knee. J Bone Joint Surg Am. 1993;75:682-93.

6. Yercan HS, Erkan S, Okcu G, Ozalp RT. A novel technique for reconstruction of the medial patellofemoral ligament in skeletally immature patients. Arch Orthop Trauma Surg. 2011;131:1059-65.

7. Placella G, Tei M, Sebastiani E, Speziali A, Antinolfi P, Delcogliano M, et al. Anatomy of the medial patello-femoral ligament: a systematic review of the last 20 years literature. Musculoskelet Surg. 2015;99:93-103.

8. Thawait SK, Soldatos T, Thawait GK, Cosgarea AJ, Carrino JA, Chhabra A. High resolution magnetic resonance imaging of the patellar retinaculum: normal anatomy, common injury patterns, and pathologies. Skeletal Radiol. 2012;41:137-48. 
9. Dirim B, Haghighi P, Trudell D, Portes G, Resnick D. Medial patellofemoral ligament: cadaveric investigation of anatomy with MRI, MR arthrography, and histologic correlation. AJR Am J Roentgenol. 2008;191:490-8.

10. Panagiotopoulos E, Strzelczyk P, Herrmann M, Scuderi G. Cadaveric study on static medial patellar stabilizers: the dynamizing role of the vastus medialis obliquus on medial patellofemoral ligament. Knee Surg Sports Traumatol Arthrosc Off J ESSKA. 2006;14:7-12.

11. Hinckel BB, Gobbi RG, Demange MK, Pereira CAM, Pécora JR, Natalino RJM, et al. Medial patellofemoral ligament, medial patellotibial ligament, and medial patellomeniscal ligament: anatomic, histologic, radiographic, and biomechanical study. Arthrosc J Arthrosc Relat Surg Off Publ Arthrosc Assoc N Am Int Arthrosc Assoc. 2017;33:1862-73.

12. Garth WP, Connor GS, Futch L, Belarmino H. Patellar subluxation at terminal knee extension: isolated deficiency of the medial patellomeniscal ligament. J Bone Joint Surg Am. 2011;93:954-62.

13. Ebied AM, El-Kholy W. Reconstruction of the medial patello-femoral and patello-tibial ligaments for treatment of patellar instability. Knee Surg Sports Traumatol Arthrosc Off J ESSKA. 2012;20:926-32.

14. Brown GD, Ahmad CS. Combined medial patellofemoral ligament and medial patellotibial ligament reconstruction in skeletally immature patients. J Knee Surg. 2008;21:328-32.

15. Nelitz M, Dornacher D, Dreyhaupt J, Reichel H, Lippacher S. The relation of the distal femoral physis and the medial patellofemoral ligament. Knee Surg Sports Traumatol Arthrosc. 2011;19:2067-71.

16. Maffulli N, Aicale R, Tarantino D, Young DA. Combined reconstruction of the medial patellotibial and patellofemoral ligaments. Muscles Ligaments Tendons J MLTJ. 2019;9 (2):194-201.

17. Arendt EA, Moeller A, Agel J. Clinical outcomes of medial patellofemoral ligament repair in recurrent (chronic) lateral patella dislocations. Knee Surg Sports Traumatol Arthrosc. 2011;19:1909-14.

18. Tompkins MA, Arendt EA. Patellar instability factors in isolated medial patellofemoral ligament reconstructions--what does the literature tell us? A systematic review. Am J Sports Med. 2015;43:2318-27.

19. Zaffagnini S, Grassi A, Marcheggiani Muccioli GM, Luetzow WF, Vaccari V, Benzi A, et al. Medial patellotibial ligament (MPTL) reconstruction for patellar instability. Knee Surg Sports Traumatol Arthrosc Off J ESSKA. 2014; 22:2491-8.

20. Rillmann P, Dutly A, Kieser C, Berbig R. Modified Elmslie-Trillat procedure for instability of the patella. Knee Surg Sports Traumatol Arthrosc Off J ESSKA. 1998:6:31-5.

21. Aulisa AG, Falciglia F, Giordano M, Savignoni P, Guzzanti V. Galeazzi's modified technique for recurrent patella dislocation in skeletally immature patients. J Orthop Sci Off J Jpn Orthop Assoc. 2012;17:148-55.

22. Sobhy MH, Mahran MA, Kamel EM. Midterm results of combined patellofemoral and patellotibial ligaments reconstruction in recurrent patellar dislocation. Eur J Orthop Surg Traumatol Orthop Traumatol. 2013;23: 465-70.

23. Giordano M, Falciglia F, Aulisa AG, Guzzanti V. Patellar dislocation in skeletally immature patients: semitendinosous and gracilis augmentation for combined medial patellofemoral and medial patellotibial ligament reconstruction. Knee Surg Sports Traumatol Arthrosc Off J ESSKA. 2012;20:1594-8.

24. Hinckel BB, Gobbi RG, Bonadio MB, Demange MK, Pécora JR, Camanho GL. Reconstruction of medial patellofemoral ligament using quadriceps tendon combined with reconstruction of medial patellotibial ligament using patellar tendon: initial experience. Rev Bras Ortop. 2016;51:75-82.

25. Galeazzi R. New applications of muscle and tendon transplant. Arch Ortop Milano. 1922;38:315-23.

26. Letts RM, Davidson D, Beaule P. Semitendinosus tenodesis for repair of recurrent dislocation of the patella in children. J Pediatr Orthop. 1999; 19:742-7.

27. Joo SY, Park KB, Kim BR, Park HW, Kim HW. The "four-in-one" procedure for habitual dislocation of the patella in children: early results in patients with severe generalised ligamentous laxity and aplasis of the trochlear groove. J Bone Joint Surg Br. 2007:89:1645-9.

28. Marcacci M, Zaffagnini S, Lo Presti M, Vascellari A, lacono F, Russo A. Treatment of chronic patellar dislocation with a modified Elmslie-Trillat procedure. Arch Orthop Trauma Surg. 2004;124:250-7.

29. Drez D, Edwards TB, Williams CS. Results of medial patellofemoral ligament reconstruction in the treatment of patellar dislocation. Arthrosc J Arthrosc Relat Surg Off Publ Arthrosc Assoc N Am Int Arthrosc Assoc. 2001;17:298-306.
30. Yang Y, Zhang Q. Reconstruction of the medial patellofemoral ligament and reinforcement of the medial patellotibial ligament is an effective treatment for patellofemoral instability with patella alta. Knee Surg Sports Traumatol Arthrosc. 2019:27(8):2599-607. https://pubmed.ncbi.n/m.nih.gov/30421164/.

31. Sadigursky D, Garcia LC, Armede M, de Oliveira LR, Carneiro RJF, Colavolpe PO. Medial patellofemoral ligament and medial patellotibial ligament reconstruction in children: preliminary results. Rev Bras Ortop. 2017;52:417-22.

32. Hetsroni I, Mann G, Dolev E, Nyska M. Combined reconstruction of the medial patellofemoral and medial patellotibial ligaments: outcomes and prognostic factors. Knee Surg Sports Traumatol Arthrosc Off J ESSKA. 2019; 27:507-15.

33. Padulo J, Oliva F, Frizziero A, Maffulli N. Basic principles and recommendations in clinical and field science research: 2018 update. Muscle Ligaments Tendons J. 2018;8:305-7.

34. Padulo J, De Giorgio A, Oliva F, Frizziero A, Maffulli N. I performed experiments and I have results. Wow, and now? Muscles Ligaments Tendons J. CIC Edizioni Internazionali. 2017;7:403.

35. Liberati A, Altman DG, Tetzlaff J, Mulrow C, Gøtzsche PC, loannidis JPA, et al. The PRISMA statement for reporting systematic reviews and meta-analyses of studies that evaluate health care interventions: explanation and elaboration. J Clin Epidemiol. 2009;62:e1-34.

36. Coleman BD, Khan KM, Maffulli N, Cook J, Wark JD. Studies of surgical outcome after patellar tendinopathy: clinical significance of methodological deficiencies and guidelines for future studies. Victorian Institute of Sport Tendon Study Group. Scand J Med Sci Sports. 2000;10:2-11.

37. Maffulli N, Aicale R, D'Addona A, Young DA, Kader DF, Oliva F. Combined medial patellofemoral and patellotibial reconstruction with soft tissue fixation in recurrent patellar dislocation. Injury. 2020;51:1867-73.

38. Lippe J, Armstrong A, Fulkerson JP. Anatomic guidelines for harvesting a quadriceps free tendon autograft for anterior cruciate ligament reconstruction. Arthrosc J Arthrosc Relat Surg Off Publ Arthrosc Assoc N Am Int Arthrosc Assoc. 2012;28:980-4.

39. Noyes FR, Butler DL, Grood ES, Zernicke RF, Hefzy MS. Biomechanical analysis of human ligament grafts used in knee-ligament repairs and reconstructions. J Bone Joint Surg Am. 1984;66:344-52.

40. Herbort M, Hoser C, Domnick C, Raschke MJ, Lenschow S, Weimann A, et al. MPFL reconstruction using a quadriceps tendon graft: part 1: biomechanical properties of quadriceps tendon MPFL reconstruction in comparison to the Intact MPFL. A human cadaveric study. The Knee. 2014;21:1169-74.

41. Hinckel BB, Gobbi RG, Kaleka CC, Camanho GL, Arendt EA. Medial patellotibial ligament and medial patellomeniscal ligament: anatomy, imaging, biomechanics, and clinical review. Knee Surg Sports Traumatol Arthrosc Off J ESSKA. 2018;26:685-96.

42. Hinckel BB, Lipinski L, Arendt EA. Concepts of the distal medial patellar restraints: medial patellotibial ligament and medial patellomeniscal ligament. Sports Med Arthrosc Rev. 2019;27:143-9.

43. Bitar AC, D'Elia CO, Demange MK, Viegas AC, Camanho GL. Randomized prospective study on traumatic patellar dislocation: conservative treatment versus reconstruction of the medial patellofemoral ligament using the patellar tendon, with a minimum of two years of follow-up. Rev Bras Ortop Engl Ed. Elsevier. 2011;46:675-83.

44. Lind M, Nielsen T, Miller L, Sørensen OG, Mygind-Klavsen B, Faunø P. No difference in outcome between femoral soft-tissue and screw graft fixation for reconstruction of the medial patellofemoral ligament: a randomized controlled trial. Arthrosc J Arthrosc Relat Surg Off Publ Arthrosc Assoc N Am Int Arthrosc Assoc. 2019;35:1130-7.

45. Kaleka CC, Aihara LJ, Rodrigues A, de Medeiros SF, de Oliveira VM, de Paula Leite Cury R. Cadaveric study of the secondary medial patellar restraints: patellotibial and patellomeniscal ligaments. Knee Surg Sports Traumatol Arthrosc Off J ESSKA. 2017:25:144-51.

46. Howells NR, Barnett AJ, Ahearn N, Ansari A, Eldridge JD. Medial patellofemoral ligament reconstruction: a prospective outcome assessment of a large single centre series. J Bone Joint Surg Br. 2012;94:1202-8.

47. Ma L-F, Wang F, Chen B-C, Wang C-H, Zhou J-W, Wang H-Y. Medial retinaculum plasty versus medial patellofemoral ligament reconstruction for recurrent patellar instability in adults: a randomized controlled trial. Arthrosc J Arthrosc Relat Surg Off Publ Arthrosc Assoc N Am Int Arthrosc Assoc. 2013;29:891-7.

48. Zhao J, Huangfu X, He Y. The role of medial retinaculum plication versus medial patellofemoral ligament reconstruction in combined procedures for recurrent patellar instability in adults. Am J Sports Med. 2012;40:1355-64. 
49. Hinckel BB, Gobbi RG, Demange MK, Bonadio MB, Pécora JR, Camanho GL. Combined reconstruction of the medial patellofemoral ligament with quadricipital tendon and the medial patellotibial ligament with patellar tendon. Arthrosc Tech. 2016;5:e79-84.

\section{Publisher's Note}

Springer Nature remains neutral with regard to jurisdictional claims in published maps and institutional affiliations.

Ready to submit your research? Choose BMC and benefit from:

- fast, convenient online submission

- thorough peer review by experienced researchers in your field

- rapid publication on acceptance

- support for research data, including large and complex data types

- gold Open Access which fosters wider collaboration and increased citations

- maximum visibility for your research: over $100 \mathrm{M}$ website views per year

At BMC, research is always in progress.

Learn more biomedcentral.com/submissions 